\title{
Hybrid Quenching In Hot Stamping Prototype Process
}

\author{
Ahmet Yılmaz*, Tuğçe Turan Abi \\ Beyçelik Gestamp Technology and Mold Industry Inc
}

\begin{abstract}
Lightweight design is getting more important issue day by day with emission restrictions. Passenger safety needs to care during lightweight design stages. Currently, hot stamping technology offers best solution for lightweight design and passenger safety issues. Hot stamping process improves materials forming limits with heat, improve strength of material via applying quenching and enable to manufacture thinner part with same strength. Process has disadvantages like, because of heating up sheet material long and high cost production line, high amount of energy consumption, high cost tool investment and finally high unit part price. Taking into account all of these issues, improvement in this process is very crucial and contributes too much to be a competitive company. That is why, an R\&D project was started to investigate hybrid quenching process which is combination of press hardening and spray cooling. Usibor1500 (22MnB5) will heat up and stamp with a prototype tool. Before the cooling process finish, taking the part out of tool at elected temperatures (450-400-350 ${ }^{\circ} \mathrm{C}$ ) and complete martensitic transition with spray cooling. Hot forming and spray cooling simulations will conduct, prototype tools and spray cooling unit will design and simulation results will compare with prototype manufacturing.
\end{abstract}

Keywords: 22MnB5; hot forming; nozzle; spray cooling; usibor1500. 